\title{
LRMSC Grade 2, Skin
}

National Cancer Institute

\section{Source}

National Cancer Institute. LRMSC Grade 2, Skin. NCI Thesaurus. Code C121171.

Patch atrophy; moderate telangiectasia; total hair loss. 